\title{
EL ESTADO COMO HACEDOR DEL TERRITORIO: El Control Territorial en Torno a la Problemática de las Inundaciones en el Chaco 1960-1990
}

JOSE RAUL ZAYALA

El presente artículo es una comunicación de la investigación que tiene por título "Configuración Espacial de los Aparatos Generadores de Control en el Estado: Inundaciones Rurales en la Provincia del Chaco, 1980 1992(1)". Se trata de describir el desarrollo de dos estrategias paralelas de control del territorio a partir de los planes y los mecanismos de incorporación de los productores a organizaciones de base, progresivamente captados por el estado provincial.

El proceso que seguimos está incorporado a una visión sistémica de la problemática de las inundaciones rurales(2) cuyos subsistemas tendrán su influencia dentro del despliegue de la articulación entre el capital, el estado y los movimientos sociales.

El artículo estará relacionado únicamente al elemento Estado. Dejando para una presentación posterior la incidencia del capital y de los movimientos sociales. A fuerza de hacer más claros los niveles problemáticos que abordamos, diríamos que el capital y los movimientos sociales acompañarán en todo momento el desarrollo del control estatal, estos elementos estarán constantemente presentes en el discurso desplegado en el artículo. La derivación principal de estas relaciones se verá reflejado por las materializaciones producidas en el territorio de estudio cual es el Domo Algodonero Chaqueño.

El objetivo total de la investigación es estructurar una visión sistémica del problema de las inundaciones rurales, donde, el aspecto que aquí analizamos configuran la interacción entre subsistemas sobre los que consideramos necesario un estudio particularizado. El espacio geográfico de referencia, (el Domo Algodonero Chaqueño) ha sido el espacio privilegiado en cuanto a planes y proyectos de manejo de aguas destinados a la producción, como veremos más adelante, por lo tanto lo particulariza y jerarquiza respectos de otros espacios de la provincia.

Como se han constituido las decisiones de control sobre el sistema de sustentación natural y la adapción al area rural del territorio chaqueño en lo relativo al manejo de las aguas es lo que pretendemos dilucidar en este artículo. 


\section{Aspectos metodológicos.}

En lo referido a los mecanismos de control asumimos como una primera dimensión del análisis, el esquema básico de un sistema controlado en base a los aportes de la cibernética y la teoría de la información.

En cuanto al funcionamiento de las instituciones (como operadores del proceso de control) y determinadas territorialidades sociales $y$ espaciales (como efector $u$ objeto de control), se comprenderá el carácter de los flujos, la posibilidad de construir un esquema totalizador y explicativo solo puede aparecer como resultado del proceso de estudio.
A los efectos, hemos asumido una segunda dimensión del que nos incorpore al conjunto de sujetos operantes en el proceso, para lo que trasladamos el esquema del sistema urbano planteado por M. Castell (3) a los aspectos más generales del análisis del territorio.

El sistema estará constituido por: a) las determinantes de la estructura social; b) la dinámica del capital y c) la acción del estado.

Esta mirada nos permite incorporar al esquema, donde las polaridades establecidas entre control en esta etapa- para asimilar la globalidad del proceso; con este esquema, se establecen relaciones y articulaciones (a través de su acción de planificación o intervención) con elementos más constitutivos de losintereses que operan sobre un espacio determinado.

La dinámica del Capital organiza los medios de producción y la organización en fuerza de trabajo, es necesaria para su lógica de reproducción como elemento vinculado a la intermediación que hace el Estado a partir de sus instituciones a diferentes escalas. Las estructuras sociales confluyen con sus prácticas sociales y tienen emergentes en ornes Científicas y Técnica, autor Arq. José Raúl Zavala, incorporado a programa de investigación Espacio y Poder. Instituto de Planeamiento Urbano y Regional de la Facultad de Arquitectura y Urbanismo de la Universidad Nacional del Nordeste.

2 Una visión sistémica de la cuestión está contenido en la investigación "ASPECTOS TERRITORIALES DE LAS INUNDACIONES RU RALES RECURRENTES EN EL CHACO ARGENTINO 1960 - 1990 Beca de Iniciación del Consejo Nacional de Investigaciones Científicas y Técnica, autor Arq. José Raúl Zavala, incorporado al programa de investigación Espacio y Poder. Instituto de Planeamiento Urbano y Regional de la Facultad de Arquitectura y Urbanismo de la Universidad Nacional del Nordeste.

3 CASTELlS MANUEL. Crisis Urbana, Estado y Participación Popular. Seminario dictado por el Dr. M. Castells en Cochabamba el 31 de Julio al 3 de Agosto de 1985, Compilador Arq. Humberto Solares S. Ed. por el Colegio de Arquitectos de Cochabamba - 1988. pág. 267 
ganizaciones políticas, movimiento sociales, o en otras. Mediatizada por la escena política constituyen ámbitos donde influenciar, ya sea en políticas del estado o en sectores corporativos, etc.

En función de este esquema, se observan los límites que pusimos al trabajo: cual es, analizar las relaciones entre diferentes aparatos del estado, sus territorios objetos del control.

Lo que queda fuera, motivo de otro trabajo, son las acciones de los movimientos sociales (Estructura Social), donde, como ejemplo, podemos señalará la rotura de rutas para abrir alcantarillas para la evacuación de las aguas durante las inundaciones de 1986 y 1990, (4) o las críticas de las Ligas Agrarias a los primeros emprendimientos de canales oficiales, a comienzos de la década del ' 70 , todas estas acciones entrarán en el juego de poder territorial, con los aparatos del estado en la producción del espacio.

El otro elemento será el Capital que para el periodo analizado observamos la dinámica del mismo, partiendo de montos de inversión, formas de licitación, ley de obra pública, las condiciones políticas que ligan a ciertos y determinados núcleos de capitalistas con los dirigentes del gobierno o encargados de las políticas de planificación del gobierno. A modo de ejemplo citamos la dinámica que tuvo en el autodenominado Proceso de Reorganización Nacional, con fuerte inversión estatal en obras públicas, tanto en vastos planes de ocupación de territorios vacíos, como el caso del Impenetrable, incluyendo obras de riego y coloniza- ción, incorporando suelo para la producción. La política de inversión en lo urbano estuvo centrado en las operatoria FONAVI. Otras obras de infraestructuras como el acueducto Barranqueras - Sáenz Peña.

\section{Definiciones operativas.}

El estado será observado a partir de lo que denominamos los aparatos y el concepto teórico que lo contendrá será: "Las prácticas ideológico - culturales se dan su existencia material en determinados aparatos-académicos y culturales en sentido estrecho, aparatos de "socialización" como la escuela, pero también informales y/o "microsociales": clubes, círculos, asociaciones civiles, empresas, la propia arquitectura, la distribución del espacio urbano, etc.-: se trata, como puede verse, de una idea mucho más amplia que la

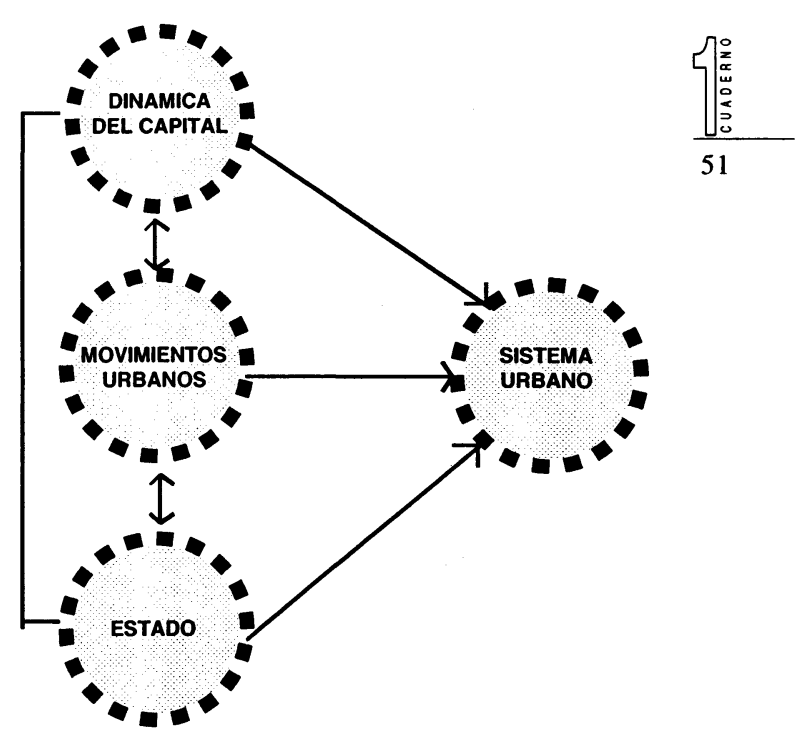


de los "aparatos ideológicos del Estado" de Althusser.

Estos aparatos tienen una "función" social (lo que no quiere decir que puedan ser reducidos a dicha función) muy específica: "organizar las masas humanas", es decir "conformar el espacio en el que los sujetos construyen su propia identidady sus pautas de conducta". (5) por lo tanto, todas las normativas, las acciones que ejecuta el estado estarán contenido por los aparatos.

¿cuáles son los aparatos del estado y sobre que territorializan? El estado establecerá distintas acciones que tendrán variadas maneras de plasmarse. Unos de los principales recursos que se ha venido distribuyendo es el suelo. La colonización de la provincia fue el principal atractivo de incorporación de población después de desplazar a los aborígenes del dominio territorial. Con la afluencia de población exógena sumada a la autóctona (6) como fuerza de trabajo, la producción primaria tiene un desarrollo importante por lo tanto, trae aparejado la inversión en infraestructuras, como caminos, ferrocarril,

5 GRUNER EDUARDO. POLITICA: ¿UN DISCURSO SIN SUJE TO? Apuntes sobre Gramsci, la cultura y las identidades. Lo Popula en América Latina: ¿Una Visión en Crisis? Editores Alberto Adrianzén Eduardo Ballón. Ed. DESCO Centro de Estudios y Promoción del Desarrollo. 1992, Lima PERU.

6 CARRERA, NICOLAS IÑIGO. Indígenas y Fronteras CAMPAÑAS MILITARES Y CLASE OBRERA CHACO, 1870 - 1930. Historia Testimonial Argentina. Documentos vivos de nuestro pasado. Centro Editor de América Latina. Bs. As. 1984.

7 ...Gran parte del creciente número de desastres ocurridos en el Tercer Mundo, como consecuencia de las inundaciones, es el resultado de actividades humanas, que aumentan la propensión de las tierras a las inundaciones $e$ incrementan su propia vulnerabilidad personal a las mismas.

Un importante factor en el incremento anual de los desastres debidos a inundaciones es el acelerado ritmo de deforestación en los países tropicales. Según un estudio conjunto FAO/PNUMA preparado en 1981, los bosques tropicales están desapareciendo a un ritmo de 7,3 millones de hectáreas anuales: 4,2 millones de hectáreas anuales en Latinoamerica; 1,8 millones en Asia y 1,3 millones en Africa. "En vista de la probabilidad de que gran parte de las vastas zonas forestales del planeta sean deforestadas en las próximas décadas, resulta imposible subrayar suficientemente su importancia en la producción de inundaciones desastrosas "DESASTRES NATURALES ¿Fuerza mayor u obra de Hombre? Anders Wijkman, Lloyd Timberlake. Instituto Internacional para el Medio Ambiente y el Desarrollo de la Cruz Roja Sueca. Publicado por el Instituto Internacional para el Medio Ambiente y el Desarrollo. Londres y Washington, D.C Febrero 1985 electrificación rural, equipamientos sociales, en síntesis equipamientos e infraestructura relacionada con la producción primaria.

El criterio productivo de extracción permanente y ampliación de fronteras agropecuaria es el principal elemento degradador (7) del territorio chaqueño, el problema de las inundaciones rurales no tenían el mismo efecto en 1960 que en la década del ochenta. Es justamente a partir del aumento de las incidencias de pérdidas de las cosechas unidas a la baja de los precios internacionales de la producción primaria, donde se acentúan las tecnologías de los aparatos estatales para controlar el problema.

El estado ha creado aparatos que controlan la tierra, infraestructuras en general, las cuestiones crediticias. Ha desplegado en un corto período de tiempo un esquema territorial de control siguiendo los intereses de la producción básicamente primaria. Para ello fue preciso desplegar inversiones, infraestructuras, equipamientos, planes de colonización, etc., para sustentar los intereses productivos. El estado ha ido incorporando mediante la estrategia de sus aparatos, territorios ganados al bosque nativo.

A medida que la inversión aumenta, o sea a medida que más se despliegan las acciones de los distintos aparatos, las consecuencia sobre su territorio de un fluido que es poco controlado como es el agua hace entrar en crisis a todo el dominio territorial desplegado.

Será precisamente la planificación, los programas de los aparatos, lo que tomaremos para anali- 
zar el despliegue de las acciones de control en torno a las aguas superficiales.

Las otras acciones que son propias del estado, como la expansión de las fronteras agropecuarias, las infraestructuras, equipamientos, si bien forma parte de las emergentes de control del estado, la dinámica que presenta cada uno de los aspectos representaría un análisis semejante al que estamos realizando en torno al control de las aguas superficiales, que dejamos para otra oportunidad

¿de que espacio geográfico hablamos?. La porción del territorio Chaqueño donde más inversión del estado se ha producido, siendo la zona productiva por excelencia. $\mathrm{Si}$ bien se intenta desarrollar otras zonas, el Domo Algodonero sigue siendo el principal polo primario de la provincia.

El Domo Algodonero o Planicie Centrochaqueña, se caracteriza por la sucesión de campos altos donde domina el bosque xerófilo de porte mediano formando islas entre amplias pampas. Sobre estos terrenos se distribuyen los mayores efectivos de población rural dedicados al monocultivo del algodón, hecho que definió un área agroindustrial autónoma en torno de la ciudad de Presidencia Roque Sáenz.

El núcleo algodonero por excelencia se extiende desde Villa Angela a Quitilipi y Sáenz Peña, y degrada paulatinamente hacia el occidente hasta terminar en una franja irregular diseñada por varios factores de los cuales el fundamental se asocia a la aridez creciente y los otros se vinculan al régimen agrario en el área de latifundios, especialmente a partir de Pinedo hacia el Sur.(8)

\section{Estrategias productivas cha- queñas.}

Describimos con esto, cuáles han sido las conjugaciones del capital y del estado que determinaron las estrategias productivas, esto nos permitirá ampliar la visión del proceso en el cual se inscriben las decisiones territoriales que estamos analizando. Consideramos imprescindible desplegar las relaciones del capitalestado en que nos encontramos hoy cuando, presentamos las acciones del estado y básicamente que territorios están siendo organizados, delimitados, controlados, a fin de presentar las condiciones necesarias para contener las estrategias de expansión de los capitales.

Para ello recurrimos a precedentes inmediatos de estrategias productivas que marcaron en el pasado, la formación de lo que hoy conocemos como la provincia del Chaco.

A mediado de 1880, el Chaco era el único territorio de la República Argentina cuyo dominio era detentado por los aborígenes.

Benjamin Victorica, Ministro de Guerra y Marina inicia en 1884 una campaña militar. El resultado fue retirar de los territorios de las cañadas del este, a los indígenas, limitándolos a operar en el centro oeste de la provincia. Las tierras tomadas fueron entregadas en concesiones.(9) Se formaron grandes propiedades destinados a la ganadería, al obraje o la producción de azúcar. También se desarrollan algunas colonias. 
A esta primera ocupación le siguió la explotación del quebracho colorado dado el descubrimiento de los usos industriales del tanino, sin descuidar la producción de postes, durmientes y maderas para la construcción.

Incorporando al proceso productivo, las fábricas para la extracción de tanino. Comenzaba la explotación industrial del bosque nativo.

En 1909 comenzó a construirse el ferrocarril que uniría la provincia del Salta con el puerto de Barranqueras en Resistencia. Dos años después cuando el ferrocarril empezó a adentrarse en territorio indígena, éste, fue "apoyado" por una segunda campaña militar culminando la tarea que no completó la campaña de 1884. Por un lado se exterminó a las tribus más bravías y por otro se estableció un ejercito de mano de obra para la nueva era que se vaticinaba, (10) la del algodón.

"A mediados de la década de 1920, un cambio en las condiciones del mercado mundial y el desarrollo del capitalismo argentino, permitieron la expansión del cultivo del algodón en la Argentina, convirtiéndose el centro oeste chaqueño en el territorio algodonero por excelencia".(11)

La historia del Chaco está ligada al desarrollo de la producción algodonera.

En el período que analizamos

9 Ob. Cit. en 6

10 ..."A fines del siglo pasado - 1895- el poblador Lorenzo Malatesta hizo las primeras experiencias de cultivo de algodón en el Chaco, en el viejo fortín San Carlos. Siguiendo su ejemplo, en el año 1900 don Juan Penco lo hace en la colonia del mismo nombre..." "Lasprimeras hectáreas cultivadas en el Chaco, fueron éstas: 1894-95, 100hec.; 1905 $2.200 ; 1906$ - 1.900; 1907 - 1.700; 1908 - 1.400; 1909- 10 - 1.182; 1910 $11-1.300 ; 1911-12-1.629 ; 1912-13-2.700$; para aumentar a 299.000 hectáreas en 1937-38...." PIACENTIN CARLOS P. LOPEZ. EVOLUCION AGRICOLA EN EL CHACO DEL REINADO DEL ALGODON A LA DIVERSIFICACION. EL CHACO ACTUAL.Breve Síntesis de Historia... Autores varios Ed. Colmena Santa Fe, Argentina 1968. 11 Ob. Cit. en 6
1960 a 1990 , las políticas territoriales del estado siempre estarán como telón de fondo los intereses de los productores y corporaciones ligadas a la producción algodonera.

Diríamos que desde los inicios los agentes productores de suelo han venido desarrollando distintas tecnologías territoriales para el mantenimiento de las tasas de ganancias.

Agregaríamos que el fenómeno de las inundaciones rurales es un factor relativamente reciente para el proceso de desarrollo del algodón, reciente en el sentido que en las últimas décadas tomó ribetes de catástrofe. Obligando al Estado a comprometer acciones para controlar las aguas superficiales.

Se tratará una vez más de presentar nuevas formas de mantener las ganancias de una fracción social con fuerte ingerencia en el estado.

\section{¿Por cuáles estrategias es- tán contenidas las planificacio- nes del estado?}

Del análisis de la documentación se desprende que en el período analizado ha habido dos estrategias para la solución de las inundaciones en la provincia.

La primera ligada a la cultura del esfuerzo del inmigrante hacedor del "porvenir", donde la problemática de las inundaciones eran solucionados por los productores agrarios. Los productores se constituyen en un importante grupo de presión logrando estatizar sus canales. Se produce una transferencia de problemas, las obras de canalización que eran financiadas por los productores son tomadas por el 
estado, o sea que la sociedad se hace cargo de los problemas de una fracción. Será un contínum de programas que perseguirán incorporar y perfeccionar los organismos que nucléan a los productores que tienen intereses comunes en el manejo de las aguas superficiales.

La segunda fue la constitución de los planes. Unas de las características que destacaremos será que los planes serán tales en la medida que constituyan un cuerpo de ideas con la suficiente potencia para ser incorporado como acción política del gobierno de turno.

No queda descartado el discurso del "esfuerzo del inmigrante", la diferencia está en la recurrencia del mismo para fortalecer al plan que al productor le es impuesto desde el estado.

A modo de referencia el ITALCONSUL será la primera referencia de plan que contiene los lineamientos de incorporación de productores que no encontramos en otros.

$Y$ por primera vez aparece un estudio a nivel provincial con la problemática de las inundaciones donde proponen en su primera etapa la necesidad de relevar datos fidedignos de climatología, hidrológico superficial y subterráneo, control de calidad de las aguas, de la eficiencia de almacenamiento de aguas pluviales, de particularidades demográficas zonales y características del relieve del área de estudio,(12) que al momento del plan no existía (¿existe actualmente?).

La segunda etapa está ligada a la preparación de un plan de largo alcance en base a la primera y al proyecto de desarrollo de la provincia del Chaco. Intentamos presentar un ejemplo de las estrategias del estado en lo referente a los planes.

Recapitulando diríamos que la estrategia de los planes está vinculado, por un lado a sectores del capital más concentrados, ligados a consultoras, a empresas constructoras, empresas de producción primaria. El capital desarrolla sectores de la producción donde las tasas de ganancias sean altas. Este fenómeno podemos observar en las consecuencias que tuvo el cambio de política habitacional a nivel nacional que en la provincia del Chaco, a principios de los `90, donde las empresas ligadas a la construcción masiva de vivienda por la operatoria FONAVI, o trasladaron sus plantas productivas a mercados más atractivos, o se achicaron a nivel de las pocas obras que el estado todavía genera. En esta situación surgieron las empresas creadas por las constructoras que giraron su actividad al sector primario, produciendo algodón, ganadería, o productos de estación con alta tecnología en la producción.

Describiremos someramente el proceso del capital que en la década del ` 60 y ` 80 , donde había una división clara entre empresa agropecuarias, las corporaciones de productores y las empresas ligadas al planeamiento y a la obra pública.

La política de los planes estaba relacionado en la década del $60^{\circ}$, $70^{\circ}$ a la problemática relación de los productores y corporaciones locales ligadas a la producción pri- 
maria con el monopolio textil nacional, había que incorporar nuevas tecnologías territoriales para mantener las tasas de ganancias.

Nosotros concluiríamos que en la actualidad el capital ligado a la burguesía local se ha diversificado teniendo interés sobre las tierras fiscales y las obras del estado.

La actual composición del capital más concentrado en la provincia son empresas cuyas actividades principales están ligadas a la obra pública y a la producción primaria, producto de los cambios en la política de la obra pública que hacíamos referencia.

Relacionando con el cuadro de Castell, donde la producción de suelo se daba en la medida que confluían el Capital, el Estado y los Movimientos Sociales. En la estrategia de los planes se cruzan casi con "exclusividad" los intereses del Capital y del Estado, máxime si en esta situación hay una utilización política que permita "publicitar" una acción de gobierno donde se le muestra a los sectores sociales excluidos de las decisiones, que esta dualidad alcanza para "solucionar los problemas" de los que no fueron consultados

\section{Proceso de estatización de las acciones de los productores: los decretos.}

El cuadro que desplegamos en la página siguiente fue confeccionado teniendo el marco de las inundaciones. Los momentos de crisis del sistema institucional generan emergentes, estos serán tomados como acciones que salen a cubrir la emergencia del momento, o al menos es presentado por el estado como tal, pero como veremos, estas situaciones son propicias para disciplinar, demarcar, conceder, dar respuestas a problemas que, de no mediar la inundación, no podrían ser aplicado.

La muestra es representativa de todos los decretos emitidos por el estado en varios momentos. Valga la aclaración que hemos seleccionados los más significativos del universo.

El primero será la inundación del `66 y el período de toma de decretos va de diciembre de 1965 hasta Julio del ` 66 , a partir de esta fecha prácticamente desaparecen las referencias al tema y encontramos emergentes importantes de las inundaciones en el ‘68 donde se forman los Consorcios Zonales. Otro emergente será en el `68 donde constituyen las COMAS. Otra inundación tomada será la del ` 68 donde los decretos permitirán hacer nuevas referencias.

Desplegado el cuadro, si bien la información volcada es abundante, nos remite describir algunas situaciones .

Primero, cuando nos referimos al Estado como uno de los elementos productores del suelo, afirmamos que esta categoría es independiente de la utilización que se haga del estado por parte del gobierno que lo detente. Para ser más explícito, al gran cuadro de las páginas siguientes, lo hemos traducido al cuadro siguiente donde por un lado están los objetivos de los decretos relevados y por otro está la división de gobiernos en democráticos y dictaduras. 


\begin{tabular}{|c|c|c|c|c|c|}
\hline $\begin{array}{l}\text { ACCION } \\
\text { ESTATAL }\end{array}$ & $\begin{array}{c}\text { DECLARACION } \\
\text { DE ZONAS DE } \\
\text { EMERGENCIA/DESASTRES }\end{array}$ & $\begin{array}{l}\text { ORGANISMOS } \\
\text { DELIBERATIVOS } \\
\text { CORP. E INST. }\end{array}$ & $\begin{array}{l}\text { COMISIONES DE } \\
\text { AYUDA SOLIDARIA E } \\
\text { INSTITUCIONAL }\end{array}$ & $\begin{array}{c}\text { CENTRALIZACION } \\
\text { DE DECISIONES EN LA } \\
\text { EMERGENCIA }\end{array}$ & $\begin{array}{c}\text { ORGANIZACION DE } \\
\text { PRODUCTORES. } \\
\text { CONTROL DE AGUAS }\end{array}$ \\
\hline DEMOCRATICO & \% & ஓ & ڤ & & \% \\
\hline DICTADURA & a & & & Һै & \%. \\
\hline
\end{tabular}

Estas dos formas del régimen no son iguales y como vemos en el cuadro, las acciones prácticamente se repiten.

Se desprende el dato donde el aspecto solidario de la situación toma un corte social amplio ya que se incorpora a la población y corporaciones e instituciones en órganos de deliberativos.

Segundo, otro aspecto impor- tante será que en otras coincidencias que tienen las acciones del estado bajo los dos régimen, será las medidas de coyunturas donde la presión de las fracciones de burguesía mas consolidadas, logran que el estado; suspenda pagos de impuestos, de juicios, ayudan a delimitar las zonas de desastre y emergencia.

Se abre un espacio amplio "al

\begin{tabular}{|c|c|c|c|c|c|}
\hline $\begin{array}{l}\text { DECRETOS, } \\
\text { DECRETOS LEY }\end{array}$ & $\begin{array}{l}\text { AREA DE } \\
\text { INFLUENCIA }\end{array}$ & $\begin{array}{l}\text { SUPERFI- } \\
\text { CIE }\end{array}$ & $\begin{array}{c}\text { OBJETIVOS } \\
\text { DE LOS DECRETOS }\end{array}$ & $\begin{array}{l}\text { ORGANISMO } \\
\text { GENERADOR }\end{array}$ & $\begin{array}{l}\text { LOS } \\
\text { TIEMPOS }\end{array}$ \\
\hline $\begin{array}{c}N^{2} 4.048 \\
\text { SE DECLARA } \\
\text { ZONA DE } \\
\text { EMERGENCIA } \\
\text { EN EL } \\
\text { DEPARTA- } \\
\text { MENTO SAN } \\
\text { FERNANDO }\end{array}$ & $\begin{array}{l}\text { Todo el ámbito } \\
\text { del citado de- } \\
\text { partamento }\end{array}$ & $\begin{array}{c}3.489 \\
\mathrm{Km}^{2}\end{array}$ & $\begin{array}{l}\text { Dada la situación creada por } \\
\text { las inundaciones, y el estado } \\
\text { actual de los habitantes ribere- } \\
\text { ños de las márgenes del Río } \\
\text { Paraná, Río Negro, Río Arazá. } \\
\text { Se faculta al ministerio de } \\
\text { Gobierno, Justicia e Instrución } \\
\text { Pública a tomar las medidas } \\
\text { necesarias para el cuidado de } \\
\text { vidas y bienes }\end{array}$ & Poder Ejecutivo & $\begin{array}{l}\text { Dto. Prom. } \\
22 / 12 / 65\end{array}$ \\
\hline $\begin{array}{l}N^{2} 4.094 \\
\text { PROHIBICON } \\
\text { DE MODIFI- } \\
\text { CACION DE } \\
\text { LAS AGUAS } \\
\text { SUP. }\end{array}$ & $\begin{array}{l}\text { Todo el ámbito } \\
\text { de la Provincia }\end{array}$ & & $\begin{array}{l}\text { Dar facultades a la Dirección } \\
\text { de Hidráulica para actuar ante } \\
\text { las distintas obras de particu- } \\
\text { lares que producen variacio- } \\
\text { nes de los cursos de aguas } \\
\text { superficiales. }\end{array}$ & $\begin{array}{l}\text { Expediente origi- } \\
\text { nado en la Direc- } \\
\text { ción de Hidráuli- } \\
\text { ca, dependiente } \\
\text { del Ministerio de } \\
\text { Economía y } \\
\text { Obras Públicas. }\end{array}$ & $\begin{array}{l}\text { Dto. Prom. } \\
28 / 12 / 65\end{array}$ \\
\hline $\begin{array}{c}\text { NNo } 136 \\
\text { DECLARA- } \\
\text { CION DE } \\
\text { ESTADO DE } \\
\text { EMERGENCIA } \\
\text { Y ZONA DE } \\
\text { DESASTRE }\end{array}$ & $\begin{array}{l}\text { Todo el ámbito } \\
\text { de la Provincia }\end{array}$ & & $\begin{array}{l}\text { Utilización de todos los me- } \\
\text { dios a su alcance para el auxi- } \\
\text { lio de pobladores afectados en } \\
\text { las ciudades, pueblos y para- } \\
\text { jes. } \\
\checkmark \text { Vehiculos de los Organis- } \\
\text { mos Provinciales a disposición } \\
\text { de la emergencia. } \\
\checkmark \text { Moratoria en beneficio de } \\
\text { los deudores bancarios que } \\
\text { han sufrido las consecuencias } \\
\text { de las Inundaciones }\end{array}$ & Poder Ejecutivo & $\begin{array}{l}\text { Dto. Prom. } \\
25 / 1 \text { / } 66\end{array}$ \\
\hline $\begin{array}{l}\mathrm{N}^{\circ} 392 \\
\text { DECLARA- } \\
\text { CION DE } \\
\text { CATASTROFE } \\
\text { A DTOS. }\end{array}$ & $\begin{array}{l}\text { Los departa- } \\
\text { mentos de } 1^{0} \\
\text { de Mayo, Río } \\
\text { Bermejo, San } \\
\text { Fernando }\end{array}$ & $\begin{array}{c}7.915 \\
\mathrm{Km}^{2}\end{array}$ & $\begin{array}{l}\text { Hacer público el estado catas- } \\
\text { trófico por el que atraviesan } \\
\text { los departamentos antes cita- } \\
\text { dos. }\end{array}$ & Poder Ejecutivo & $\begin{array}{l}\text { Dto.Prom. } \\
25 / 2 / 66\end{array}$ \\
\hline
\end{tabular}




\begin{tabular}{|c|c|c|c|c|c|}
\hline $\begin{array}{l}\text { DECRETOS, } \\
\text { DECRETOS LEY }\end{array}$ & $\begin{array}{l}\text { AREA DE } \\
\text { INFLUENCIA }\end{array}$ & SUPERFICIE & $\begin{array}{c}\text { OBJETIVOS } \\
\text { DE LOS DECRETOS }\end{array}$ & $\begin{array}{l}\text { ORGANISMO } \\
\text { GENERADOR }\end{array}$ & $\begin{array}{l}\text { LOS } \\
\text { TIEMPOS }\end{array}$ \\
\hline $\begin{array}{c}\text { No } 457 \\
\text { SE CREA LA } \\
\text { COMISION DE } \\
\text { RECONSTRUC- } \\
\text { CION, ESTU- } \\
\text { DIOSY } \\
\text { CONTRALOR } \\
\text { DE AGUAS } \\
\text { DE LA } \\
\text { PROVINCIA }\end{array}$ & $\begin{array}{l}\text { Todo el ámbito } \\
\text { de la Provincia }\end{array}$ & - & $\begin{array}{l}\text { Tomar en forma integral el problema } \\
\text { de las inundaciones. } \\
\checkmark \text { Integrarán esta comisión los re- } \\
\text { presentantes de la Prov. del Chaco, } \\
\text { Munc. de Resistencia, Barranque- } \\
\text { ras, Puerto Vilelas, Inst. Geográfico } \\
\text { Militar, INTA. Dicc. Nacional de Via- } \\
\text { lidad, C.G.T.,C.G.E., Bco. de la Prov. } \\
\text { del Chaco, Consejo Profs. de Agr. } \\
\text { Arq. e Ing, del Chaco, U.N.N.E, } \\
\text { U.C.A.L, F.A.C.A., Fed. Agr. Argen- } \\
\text { tina. Sociedad Rural. } \\
\sim \text { Funciones a- evaluación general } \\
\text { de los daños causados por la inun- } \\
\text { dación b- problemas derivados de } \\
\text { las inundaciones y planificación de } \\
\text { las obras indispensables para su } \\
\text { contralor c- estudio para la reubica- } \\
\text { ción de población, las obras nece- } \\
\text { sárias. }\end{array}$ & Poder Ejecutivo. & $\begin{array}{l}\text { Dto.Prom. } \\
7 / 3 / 66\end{array}$ \\
\hline $\begin{array}{l}\text { NN389 } \\
\text { SE CREA UNA } \\
\text { COMISION } \\
\text { PERMANENTE } \\
\text { DE AYUDA A } \\
\text { LOS INUNDA- } \\
\text { DOS }\end{array}$ & $\begin{array}{l}\text { Todo el ámbito } \\
\text { de la Provincia }\end{array}$ & - & $\begin{array}{l}\text { Ante la magnitud del fenómeno de } \\
\text { las inundaciones y para darle una } \\
\text { organización a las numerosas co- } \\
\text { lecta para los damnificados } \\
\checkmark \text { se crea una comisión con perso- } \\
\text { nas vinculadas al quehacer chaque- } \\
\text { ño. }\end{array}$ & Poder Ejecutivo & $\begin{array}{l}\text { Dto.Prom. } \\
25 / 2 / 66\end{array}$ \\
\hline $\begin{array}{c}\text { NN } 644 \\
\text { EL GOBIERNO } \\
\text { PROVINCIAL } \\
\text { TOMA A SU } \\
\text { CARGO EL } \\
\text { SANEAMIENTO } \\
\text { INTEGRAL DEL } \\
\text { CONURBANO } \\
\text { RESISTENCIA - } \\
\text { BARRANQUERAS } \\
\text { - VILELAS - } \\
\text { FONTANA - } \\
\text { CACUI }\end{array}$ & & - & $\begin{array}{l}\text { La Comisión Provincial de Recons- } \\
\text { trucción recomienda ejecutar la } \\
\text { primera etapa del llamado Plan } \\
\text { SANINDTEC } \\
\checkmark \text { La firma asesorará el orden de } \\
\text { prioridades recomendables e inver- } \\
\text { siones por sucesivas etapas, los cri- } \\
\text { terios a aplicar al movilizar los recur- } \\
\text { sos, retribuciones y gastos proba- } \\
\text { bles estimados o a prever, como así } \\
\text { también deberan presentar la actua- } \\
\text { lización del proyecto, estudios de } \\
\text { factibilidad y funcionamientos eco- } \\
\text { nómicos, que abonen la realización } \\
\text { de las obras ante organismos finan- } \\
\text { cieros públicos o privados, naciona- } \\
\text { les o extrajeros. }\end{array}$ & Poder Ejecutivo & $\begin{array}{l}\text { Dto.Prom. } \\
30 / 3 / 66\end{array}$ \\
\hline $\begin{array}{c}N^{2} 1.129 \\
\text { Se suscribe } \\
\text { contrato con } \\
\text { ITALCONSULT } \\
\text { ARGENTINA } \\
\text { S.A.C.I. y F. }\end{array}$ & & - & $\begin{array}{l}\text { Por recomendación de la Comisión } \\
\text { Provincial de Reconstrucciónes y } \\
\text { Estudios se locacionan los servicios } \\
\text { profesionales de la citada firma. } \\
\checkmark \text { Elaboración de un estudio prelimi- } \\
\text { nar de la cuenca del Río Tapaenagá } \\
\text { sobre sus recursos, problemas y } \\
\text { posibles soluciones, así como la de- } \\
\text { terminación de un área piloto de } \\
\text { desarrollo dentro de dicha cuenca o } \\
\text { su zona de influencia. } \\
\checkmark \text { Elaboración de un informe de fac- } \\
\text { tibilidad quecontenga el proyecto de } \\
\text { obras recomendadas. } \\
\checkmark \text { Preparación de documentación } \\
\text { para el llamado a licitación y reco- } \\
\text { mendaciones para la acción especi- } \\
\text { fica. }\end{array}$ & Poder Ejecutivo. & $\begin{array}{l}\text { Dto.Prom. } \\
10 / 6 / 66\end{array}$ \\
\hline
\end{tabular}




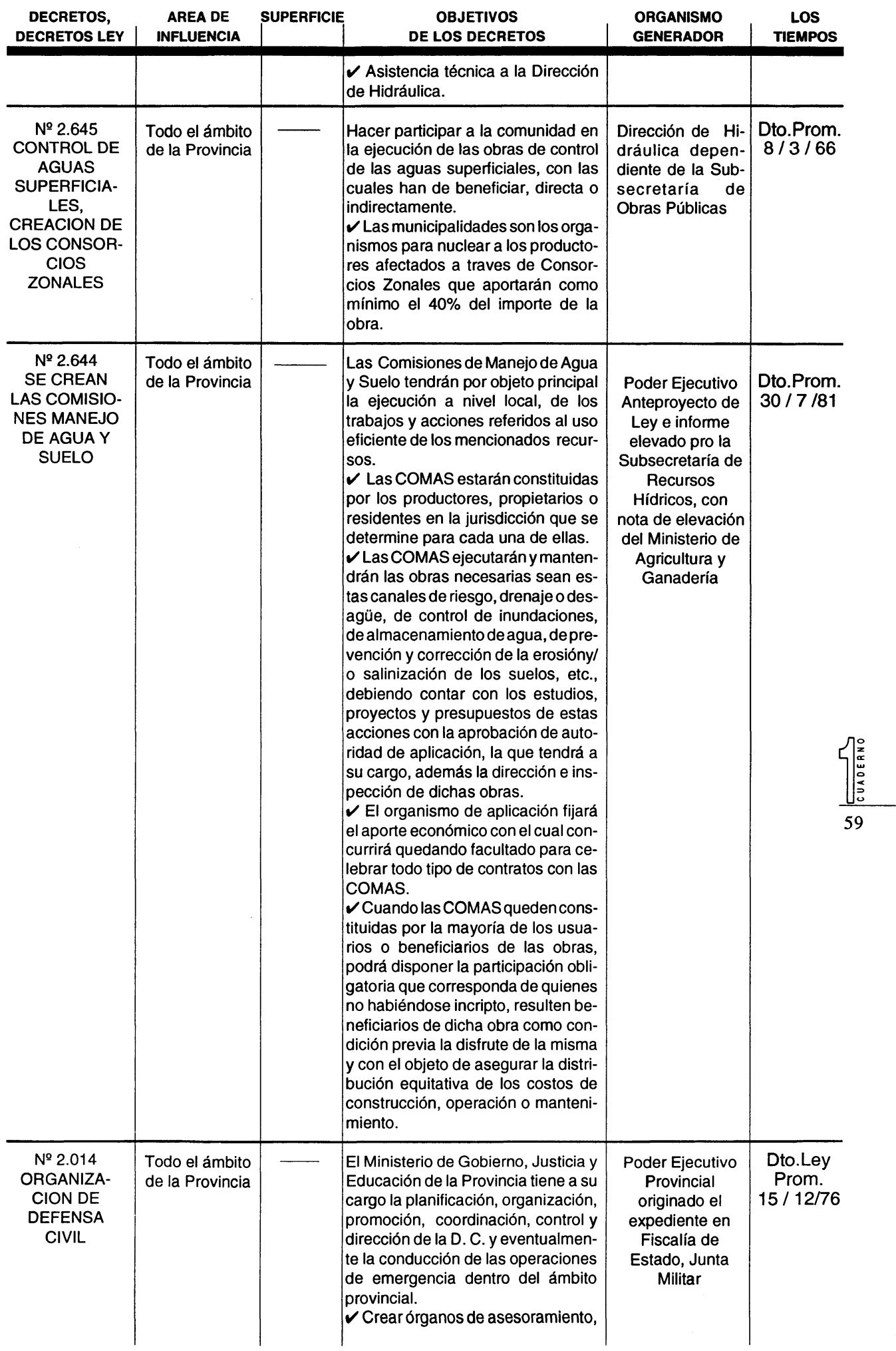




\begin{tabular}{|c|c|c|c|c|c|}
\hline $\begin{array}{l}\text { DECRETOS, } \\
\text { DECRETOS LEY }\end{array}$ & $\begin{array}{c}\text { AREA DE } \\
\text { INFLUENCIA }\end{array}$ & SUPERFICIE & $\begin{array}{c}\text { OBJETIVOS } \\
\text { DE LOS DECRETOS }\end{array}$ & $\begin{array}{l}\text { ORGANISMO } \\
\text { GENERADOR }\end{array}$ & $\begin{array}{l}\text { LOS } \\
\text { TIEMPOS }\end{array}$ \\
\hline & & & $\begin{array}{l}\text { ejecución y control de la D. C. a nivel } \\
\text { Prov. y Municipal. } \\
\text { Disponer la realización de estu- } \\
\text { dios e investigaciones relativas a las } \\
\text { zonas suceptibles de ser afectadas } \\
\text { por desastres naturales. }\end{array}$ & & \\
\hline $\begin{array}{c}N^{2} 625 \\
\text { DECLARASE } \\
\text { ZONA DE } \\
\text { DESASTRE Y } \\
\text { EMERGENCIA } \\
\text { AGROPECUARIA }\end{array}$ & Ver decreto & & $\begin{array}{l}\text { Las medidas que se adopten para } \\
\text { paliar las inundaciones serán aplica- } \\
\text { das a los productores que acrediten } \\
\text { los daños producidos mediante un } \\
\text { certificado otorgado por las Subco- } \\
\text { misiones Zonales de Emergencia } \\
\text { Agropecuaria. }\end{array}$ & $\begin{array}{l}\text { Poder Ejecutivo. } \\
\text { Ministerio de } \\
\text { Agricultura y } \\
\text { Ganadería }\end{array}$ & $\begin{array}{l}\text { Dto. } \\
\text { Prom. } \\
8 / 4 / 86\end{array}$ \\
\hline $\begin{array}{l}N^{2} 731 \\
\text { SUSPENSION } \\
\text { DE JUICIOS } \\
\text { CONTRA } \\
\text { CONTRIBUYEN- } \\
\text { TES }\end{array}$ & $\begin{array}{l}\text { Todo el ámbito } \\
\text { de la Provincia }\end{array}$ & & $\begin{array}{l}\text { Suspender la iniciación de juicios de } \\
\text { apremios por cobro de deudas fisca- } \\
\text { les impositivas a los contribuyentes } \\
\text { y/o responsables radicados en las } \\
\text { zonas declaradas de desastre y } \\
\text { emergencia agropecuaria conforme } \\
\text { los términos del Decreto № } 625 / 86\end{array}$ & $\begin{array}{l}\text { Poder Ejecutivo. } \\
\text { Ministerio de } \\
\text { Obras y Sercícios } \\
\text { Públicas }\end{array}$ & $\begin{array}{c}\text { Dto. } \\
\text { Prom. } \\
23 / 4 / 86\end{array}$ \\
\hline $\begin{array}{c}N^{\circ} 794 \\
\text { REORDENAMENTO } \\
\text { DE LOS } \\
\text { CONTRATOS DE } \\
\text { OBRAS } \\
\text { CONSTRUIDAS } \\
\text { A TRAVES DEL } \\
\text { I.P.D.V. }\end{array}$ & & & $\begin{array}{l}\text { Disponer en cada contrato de obra } \\
\text { del instituto resolverá los cambios de } \\
\text { los cronogramas y erogaciones con } \\
\text { cargo al cronograma y crédito asig- } \\
\text { nado por el FO.NA.VI. }\end{array}$ & $\begin{array}{l}\text { Poder Ejecutivo } \\
\text { Ministerio de } \\
\text { Obras y Sercícios } \\
\quad \text { Públicas } \\
\text { Ministerio de Go- } \\
\text { bierno Justicia y } \\
\text { Educación }\end{array}$ & $\begin{array}{c}\text { Dto. } \\
\text { Prom. } \\
20 / 4 / 86\end{array}$ \\
\hline $\begin{array}{c}N^{\circ} 815 \\
\text { TRANSFEREN- } \\
\text { CIA DE FONDO } \\
\text { A LOS MUNICI- } \\
\text { PIOS EN } \\
\text { CONCORDAN- } \\
\text { CIA CON LA LEY } \\
\text { DE DEFENSA } \\
\text { CIVIL }\end{array}$ & $\begin{array}{l}\text { Los municipios } \\
\text { del decreto } \\
\text { que fija las } \\
\text { zonas de } \\
\text { desastre y } \\
\text { emergencia }\end{array}$ & & $\begin{array}{l}\text { En concordancia con la ley de facto } \\
\text { de defensa civil se faculta al Ministro } \\
\text { de Gobierno, Justicia y Educación a } \\
\text { relizar transferencia de fondos a los } \\
\text { municipios que lo soliciten. }\end{array}$ & $\begin{array}{l}\text { Poder Ejecutivo. } \\
\text { Ministerio de } \\
\text { Gobierno Justicia } \\
\text { y Educación }\end{array}$ & $\begin{array}{c}\text { Dto. } \\
\text { Prom. } \\
28 / 4 / 86\end{array}$ \\
\hline $\begin{array}{c}N^{2} 823 \\
\text { PRORROGA } \\
\text { DEL IMPUESTO } \\
\text { EN ZONAS } \\
\text { AFECTADAS }\end{array}$ & $\begin{array}{c}\text { Ver decreto } N^{2} \\
625\end{array}$ & & $\begin{array}{l}\text { Se prorrogan los impuestos de in- } \\
\text { gresos brutos y el inmobiliario rural a } \\
\text { los que puedan demostrarestarafec- } \\
\text { tados por las inundaciones en un } \\
\text { todo de acuerdo con el decreto № } \\
625 / 86\end{array}$ & $\begin{array}{l}\text { Poder Ejecutivo } \\
\text { Provincial } \\
\text { Ministerio de } \\
\text { Obras y Sercícios } \\
\text { Públicas }\end{array}$ & $\begin{array}{c}\text { Dto. } \\
\text { Prom. } \\
29 / 4 / 86\end{array}$ \\
\hline $\begin{array}{c}\text { LEY N } N^{\circ} 3.203 \\
\text { CODIGO DE } \\
\text { AGUAS }\end{array}$ & $\begin{array}{l}\text { Todo el ámbito } \\
\text { de la Provincia }\end{array}$ & & $\begin{array}{l}\text { Sistema normativo que orienta la } \\
\text { política hídrica provincial, regula las } \\
\text { relaciones jurídico - administrativas } \\
\text { que tengan por objeto los recursos } \\
\text { hídricos y las obras necesarias para } \\
\text { un adecuado aprovechamiento. } \\
\text { Crea un único organismo de cen- } \\
\text { tralización control y ejecución de pro- } \\
\text { gramas para el uso del recurso agua, } \\
\text { subordinado los actuales organis- } \\
\text { mos dedicados al manejo del recur- } \\
\text { so. }\end{array}$ & $\begin{array}{c}\text { Poder Ejecutivo } \\
\text { Poder Legislativo }\end{array}$ & $\begin{array}{l}\text { Ley. } \\
\text { Prom. } \\
30 / 12 / \\
86\end{array}$ \\
\hline
\end{tabular}


amparo" de las inundaciones donde fracciones sociales redefinen territorios, por lo tanto control.

Como habíamos adelantado las emergentes del estado, en términos de control territorial abarcan una amplia gama de problemáticas. Por lo tanto cada una de las categorías del cuadro precedente merecería un análisis detallado.

Tercero; El punto anterior hacía mención a acciones coyunturales, de aplicación inmediata, de efectos próximos.

Otras medidas son tomadas en el marco de la emergencia. No se corresponden con efectos que faciliten la solución de urgencia de una inundación. Nos referimos a la creación de organismos incorporadores de productores para el control de las aguas. Pasará un período importante hasta que estas organizaciones empiecen a poner su impronta en el territorio.

Estarán supeditadas al tiempo, al desarrollo de las relaciones, del grado de organización que se impongan como condicionantes internos.

Toda esta lógica tendrá sentido en la medida que se articule con decisiones del Estado que permitan funcionar a las organizaciones de los productores.

El Estado y los productores (Estructura Social) mediatizarán la coyuntura de las inundaciones para establecer y optimizar estrategias de estatización de las acciones de esa fracción social.

Será precisamente el desarrollo pormenorizado de estos organismos de planificación-acción, que durante los últimos veinticinco años han armado un nuevo paisaje hídrico en la provincia del Chaco lo que a continuación describiremos.

\section{¿cuál es el proceso de las orga- nizaciones COMAS?}

La creación en 1957 de la provincia del Chaco, hace que su historia sea tan reciente que facilita reconstruirla, (13) en un ámbito no muy desarrollado como es una cierta historia de las políticas territoriales, donde el Estado era más asible por parte de los pobladores.

Será entonces en los inicios de la década del sesenta, que encontramos tempranamente la incorporación de los pobladores a comisiones o grupos vecinales cuyo objetivo es la construcción de distintas obras de infraestructura para el manejo de las aguas superficiales.

Primer momento La idea que un lector se hace reconstruyendo la génesis de las actuales Comisiones de Manejo de Agua y Suelo, es que en sus inicios las decisiones sobre el agua tenía un carácter democrático, en el sentido que la unión de vecinos era una condición necesaria para constituir organizaciones con objetivos precisos de ordenar los problemas que causaban los excesos de agua por lluvia. También los municipios proyectaban y ejecutaban distintas obras que hacían al control de las aguas superficiales. Convivían ambas organizaciones en las mismas ciudades, más bien era visto como símbolos de solidaridad entre los ciudadanos que compartían un mismo interés de mejorar las condiciones del territorio que compartían. Estamos hablando de los primeros años de la 
década del sesenta.

Segundo momento. El desarrollo posterior de estas organizaciones entraron en conflicto en 1966 donde registramos el decreto $\mathrm{N}^{\mathrm{o}}$ 4.094(14) que pone límites a los hasta entonces organismos no oficiales que reunía a los productores rurales. El estado pretendía con esta medida hacer un corte en la construcción de canales y demás obras que venían realizando los productores y municipios, e imponer su hegemonía en la proyectación y ejecución de obras que hacían a las aguas superficiales. Quedaba atrás (al menos formalmente) la iniciativa de productores que durante todo el primer quinquenio habían ejercido una territorialidad.

Aquí tendríamos que establecer dos campos, el primero está relacionado con la génesis de la estrategia estatal de incorporación de los productores a su política del agua, que es la que desplegaremos a continuación, y el segundo; (será otro artículo) un estudio de la constitución de los productores que en forma paralela a lo instituido o sea que por afuera de las instituciones siguieron proyectando y ejecutando obras que hacían y hacen a sus intereses.

“...Que en razón que numerosos propietarios poseedores de predios rurales modifican los cursos naturales de las aguas superficiales, construyendo diques de contención en unos casos o desviando las aguas mediante canales, tratando de evitar la acumulación de aguas en su propiedad, pero perjudicando a terceros..." "A partir de la fecha del pre-

14 PROHIBICION DE MODIFICACION DE LAS AGUAS SUPERFI CIALES. Decreto del poder Ejecutivo. Boletín Oficial de la Provincia del Chaco. N2 2327 del lunes 10 de Enero de 1966

15 Ob. Cit. en 5

16 PROGRAMA PARA USO $Y$ CONTROL DE LAS AGUAS EN LA PROVINCIA DEL CHACO. ITALCONSULT. Argentina S.A.C.I. y F. Informe Preliminar, página 348 y suc. sente decreto, queda prohibida en el ámbito provincial, por parte de particulares $u$ organismos oficiales, la construcción de toda obra que altere los cursos naturales de las aguas superficiales ya sean tajamares, zanjas, canales, compuertas, etc., como también aquellos que, so pretexto de mejoras en la vialidad modifiquen dichos cursos en forma injustificada."(15)

Con esta posición el poder ejecutivo intenta "barajar y dar de nuevo", porque no solo se disponía a disciplinar a los productores si no que también a los municipios y otros organismos del estado que también hacían su "contribución" en la distribución de las aguas superficiales.

Tercer momento El capítulo que sigue en la estrategia del estado lo da el estudio que el Poder Ejecutivo provincial, encomienda a la consultora ITALCONSUL Argentina S.A.C.I. y F. (desarrollaremos en profundidad más adelante) donde después de relevar las distintas obras realizadas por las organizalciones de productores, municipio como empresas, recomienda "Promover el esfuerzo cooperativo para que, mediante Consorcios de Saneamiento Urbano y Rural, faciliten la ejecución de los programas a nivel de usuarios interesados y beneficiarios." (16)

Esta recomendación no pudo materializarse en el gobierno del escribano Deolindo F. Bittel ya que un golpe militar impidió que realizara su tarea. Pero los militares no han sido desconsiderados y el 8 de marzo de 1968 se publica en el Bo- 
letín Oficial (17) el decreto que da forma institucional a los Consorcios Zonales, y el considerando dice "Que asimismo los propietarios o arrendatarios de tierras ante las avalanchas de aguas que se desplazan por sus predios construyen terraplenes y canales, para preservar sus campos, agravando aún más la situación."..."Que es un deber de buen Gobierno buscar la unión entre todos los ciudadanos y a la vez hacer participar a la comunidad en la ejecución de las obras, con las cuales se han de beneficiar, directa o indirectamente" . Aquí está la preocupación democrática de los militares interesados en no tomar decisiones sobre el territorio sin la participación de la comunidad. Sigue.

"Que las municipalidades son los órganos indicados para propender al nucleamiento de los productores afectados por las aguas de lluvias y que incluso deben, por intermedio de Comisiones Especiales colaborarcon la Dirección de Hidráulica en la planificación de estudios y obras para Control de Aguas superficiales.".

Con el artículo del decreto que reproducimos seguidamente, quedaban unificadas las dos líneas de acción que con anterioridad habíamos descripto, tenían en un solo aparato los productores y los municipios, estando el control de estos consorcios en los delegados políticos de los militares como eran los intendentes.

"Art. 2. A los fines precedente expuestos, las Municipalidades formarán una Comisión honoraria para Obras de Control de Aguas Superficiales, de cinco miembros, que presi- dirá el intendente y cuyos otros integrantes serán vecinos de distintas zonas de jurisdicción local interesados en obras de esa naturaleza, siendo sus principales funciones las siguientes: a) Propender a la constitución de los Consorcios, que tendrán a su cargo la construcción y conservación de obras de canalización; $b$ ) Aconsejar sobre las obras a construir; c) Colaborar con los Consorcios en las gestiones para la donación de terrenos materiales o servidumbres necesarios para la apertura, rectificación o limpieza de canales; d) Supervisar el funcionamiento de los consorcios; e) Controlar la conservación de las obras ejecutadas; cuando por razones de jurisdicción sea necesario, entre varias $\mathrm{Mu}$ nicipalidades podránformar una sola Comisión. En tal caso y de común acuerdo entre la Dirección de Hidráulica y esas Municipalidades, se designará al Intendente que presidirá la Comisión; f) Intervenir en la Administración de las aguas Superficiales, encausadas mediante canales."

Con estas estructuras normativas el estado opera por más de una década en la cuestión hídrica. La hegemonía de la planificación y ejecución de obras mediante estos mecanismos, no evitaron las denuncia por parte de los productores agrupados en las Ligas Agrarias Chaqueñas,(18) de la construcción de canales "inunda chacras" en Rio Muerto, realizados por la dirección de hidráulica de la provincia.

Cuarto momento Otra vuelta a la cuestión le dará el decreto №

17 CONTROL DE AGUAS SUPERFICIALES, Decreto № 2.645 Boletín Oficial de la Provincia del Chaco № 2.752

18 EL CAMPESINO, Organo Oficial de las Ligas Agrarias Chaqueñas, Año 1 NN $^{2}$ "Que Renuncie Jerabek" página 6 y 7 de Abril de 1973. 
2.644 (19) donde se crean las Comisiones de Manejo de Agua y Suelo donde "La medida responde a la necesidad de ordenar la ejecución de obras que, en forma individual e indiscriminada llevan a cabo los productores, y que afectan el normal escurrimiento de las aguas. Asimismo es necesario reparar los prejuicios directos que traen aparejadas las inundaciones sobre los suelos, tales como erosión y salinización de los mismos, y primordialmente, iniciar las acciones inmediatas en el área de los Bajos Submeridionales, destinadas a la recuperación de las tierras para la producción." "Los productores organizados en las respectivas Comisiones, constituyen el mecanismo más idóneo para cumplir con los objetivos propuestos, toda vez que ello implica participación de la comunidad que se ha de beneficiar directamente con las acciones a realizar, y que los beneficiarios inmediatos serán responsables de la conservación de las obras que se ejecutan."

Hay situaciones irresolutas, aparentemente en la década en que media de un decreto a otro, por un lado los militares siguen preocupados por la incorporación de la comunidad en las decisiones territoriales, y por otro encontramos que

19 CREASE COMISIONES DE MANEJO DE AGUA Y SUELO. Decreto Ley № 2.644 Boletín Oficial de la Provincia del Chaco № 4.792 del Viernes 30 de Octubre de 1981.

20 CODIGO DE AGUAS DE LA PROVINCIA DEL CHACO. Cámara de Diputados de la Provincia del Chaco. Boletín Oficial de la Provincia del Chaco № 5.587, 30 de Diciembre de 1986.

21 LEY № 3.542, Modifica el nombre de Instituto Provincial del Agua contenida en la ley № 3.230, por Instituto Provincial del Agua del Chaco, sancionado el 27 de Abril de 1990.

22 Ob.Cit. en 4 ; es un relato del despliegue de los distintos aparatos estatales que en forma directa o por sus acciones tienen efectos inducidos en lo referente al manejo de las aguas superficiales en el Chaco, en 1986 relevamos 17 aparatos, muchos de ellos pertenecen al estado o son parte de la estrategia del mismo, al sancionarse la ley № 3.230, nada ha cambiado a 1993, coexisten todos los aparatos enumerados y la centralización no se ha producido. Agregaríamos que en la actualidad estamos en una etapa de internacionalización en lo referente al control territorial ya que se ha formado una comisión de Banco Mundial que esta accionando específicamente en la cuestión de las inundaciones en la provincia. los productores continúan accionando sobre las aguas superficiales sin el control del estado. Cada decreto busca reafirmar la soberanía del estado.

Con este cuerpo jurídico se operó hasta 1986 donde con la sanción de la ley $\mathrm{N}^{\circ} 3.230,(20)$ la provincia tendrá por primera vez de una legislación de fondo, por otra parte crea el Instituto Provincial del Agua del Chaco(21) único organismo(22) a partir de la sanción de la ley de centralizar la planificación y ejecución de todo lo referente a aguas superficiales y subterráneas.

En lo referente a las Comisiones de Manejo de Agua y Suelo, “...están integradas por los productores, propietarios o residentes en la jurisdicción que se determine para cada una de ellas. Funcionarán como personas jurídicas de derecho público, no estatales tendiente a asegurar la más racional y provechosa utilización del agua y los otros recursos naturales ..." . Tienen la amplitud de incorporar a cualquier interesado en participar en la comisiones y no solo a los beneficiarios directos o indirectos de las obras como lo estipulaba los anteriores decretos. Si bien la caracterización de ser "personas jurídicas de derecho público, no estatales", es un aspecto formal ya que su dependencia de las decisiones de diversos aparatos del estado las vincula a una estrategia estatal en lo referente a la manera de distribuir el control territorial por parte del estado.

Una reflexión en este punto del relato nos lleva a plantear que la larga estrategia de incorporación de productores a la política del es- 


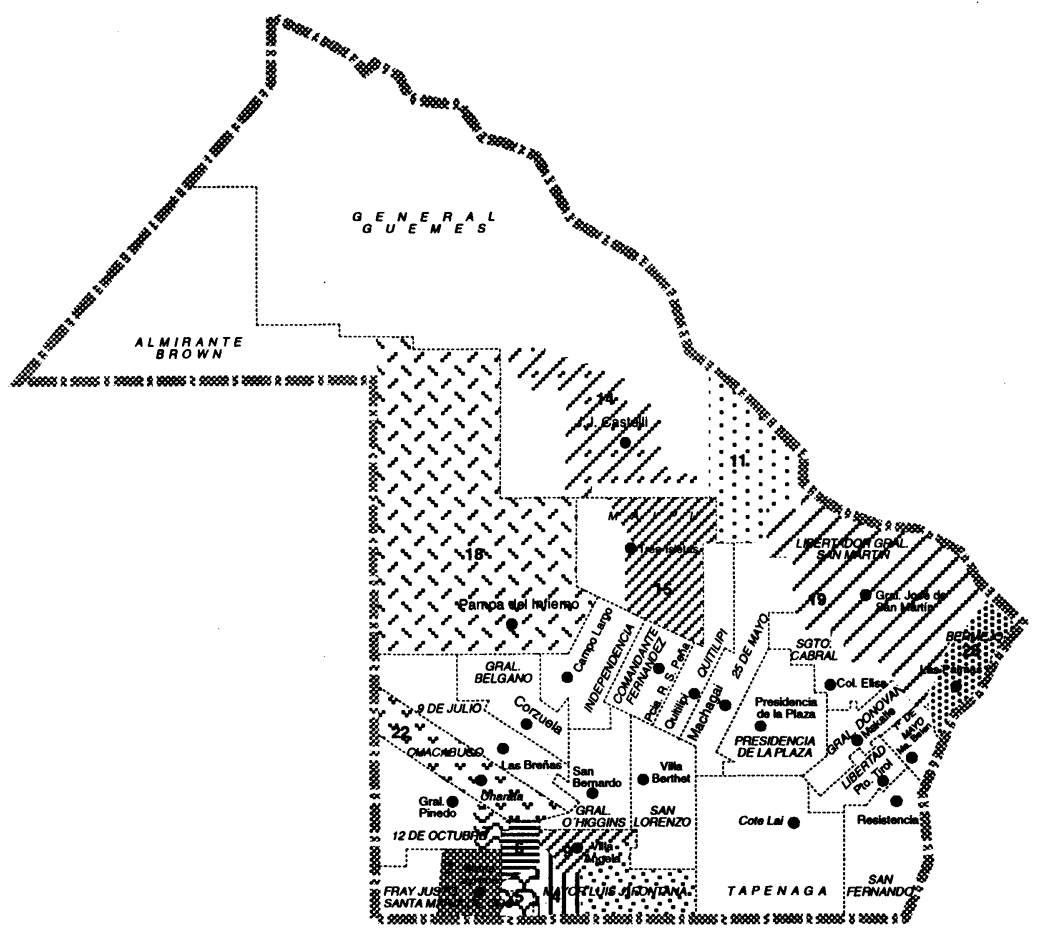

TERRITORIALIDAD DE LAS COMISIONES DE AGUA Y SUELO 1986 - 1990

tado es un planteo de distintas fracciones de la burocracia intermedia que ha mantenido los lineamientos a lo largo del tiempo, y que institucionalizan su posición trasladando como acción política a los gobiernos de turno.

El otro extremo de esta dualidad es en la capacidad de transferir al estado los problemas de una fracción, como decíamos antes, es más, los productores estatizarán sus intereses, encontrando en el estado el agente financiador - legalizador.

Un análisis del proceso de conformación de los aparatos incorporadores de productores tendría que contener el correlato en lo territorial de los distintos decretos descriptos. El dato a construir perseguiría dar respuesta a: ¿Qué territorios fueron incorporados por cada uno de los decretos? ¿Qué tipos de obras se realizaron?, ¿Qué inversión en cada uno de los distritos en que fueron divididos los consorcios o comisiones?.

La construcción de este dato todavía esta en proceso, creemos que allí encontraremos nuevos elementos empíricos que nos remitirán a nuevas proposiciones, queda pues planteado el problema.

Lo que hemos podido desarrollar son los datos actuales de la Comisiones de Manejo de Agua y Suelos (COMAS), mas precisamente los del período 1986 a 1990.

Aquí nos preguntamos. ¿Como se distribuyen en el territorio las COMAS? ¿Que han hecho en materia de manejo de las aguas superficiales? ¿En que manera se distribuyó la inversión estatal en el territo- 


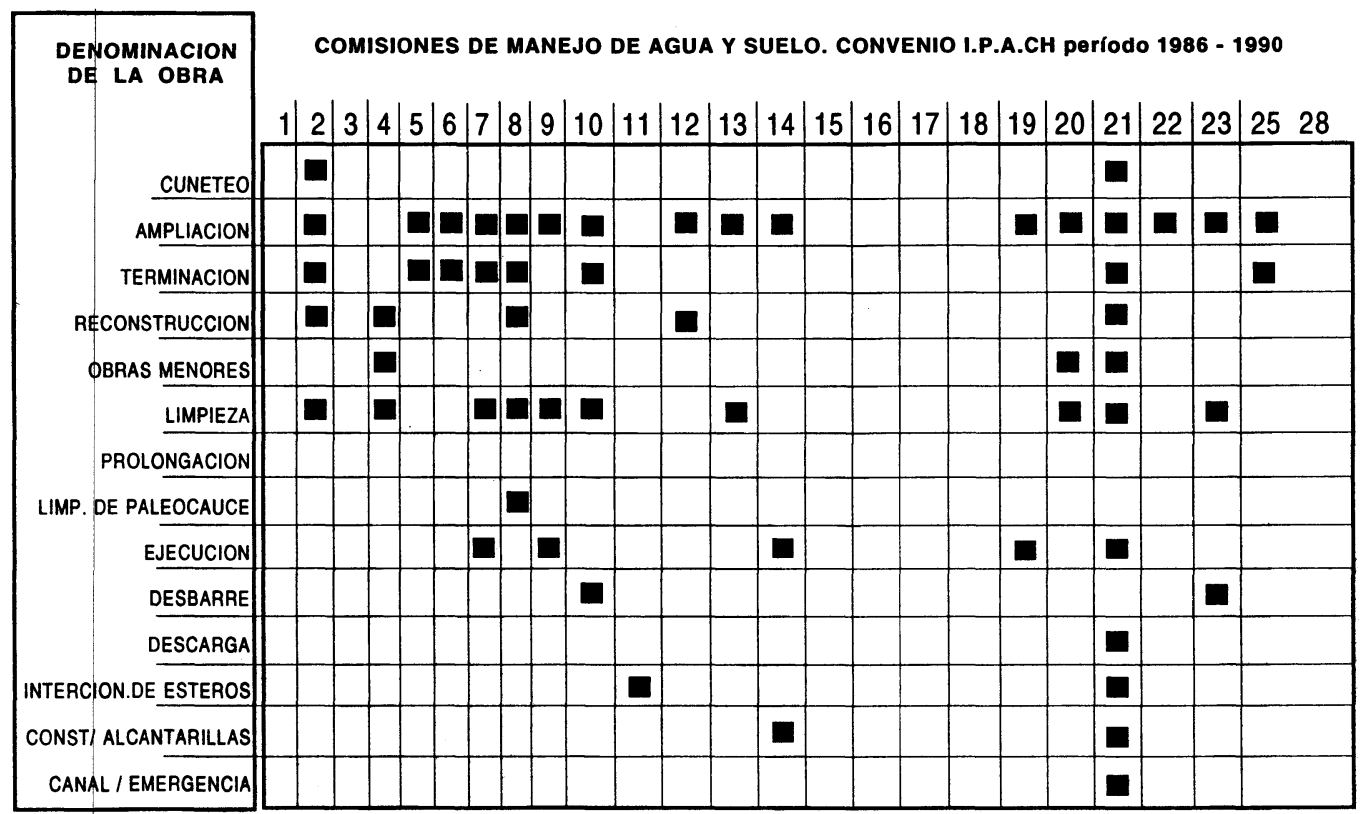

rio controlado por las mismas?.

Una primera respuesta sería que las COMAS, son distribuidas territorialmente, casi con exclusividad en el Domo Algodonero, como muestra el mapa.

Una segunda, al observar el cuadro de inversiones del período 19861990, donde el $63 \%$ de la inversión estatal estuvo dirigida, al Domo, el

COMISIONES DE MANEJO DE AGUA Y SUELO INVERSIONES 1986 - 1990 resto del porciento se redistribuyen en las zonas productivas marginales. Subrayaríamos, dentro de esta última, las comas 11 y 14 donde los montos unitarios son muy importante en relación con los montos unitarios del conjunto de las $\mathrm{CO}$ MAS del Domo.

Y la tercera, está referido a las obras que produjeron, siendo importante el rubro de ampliación de canales, terminación y limpieza.

De toda esta información se desprende que las COMAS, han funcionado como empresas de servicio cuya dinámica acompaña a la emergencia que genera cada inundación, queda al desculierto la incapacidad de los canales para conducir todo el fluiilo.

La carencia de una planificación que tenga en claro la cantidad de líquido que debería conducir los canales. de qué lugar a dónde, deja al descubierto la desorganización con que - se at aca un problema único cual es conducir el agua superficial dentro de una problemática am- 
biental que lo contiene, donde la acción de las COMAS, está reducido a una parcialidad que entra en contradicción con el conjunto

\section{Estructuración de la estrategia de los planes}

La provincia tiene una cantidad importante de planes sobre su territorio. Unas de las particularidades será que muy pocas obras fueron concluidas, la información está dispersa imposibilitando por el momento relevar que quedó de cada uno de los planes emprendidos. Los planes proyectados en estos treinta años, básicamente tomaron los siguientes aspectos, a) Obras de control de aguas y b) Obras para captar y abastecer de agua a las poblaciones, propósitos múltiples.

A solo efecto de dar una descripción somera del proceso de consolidación del estado provincial, establecemos tres momentos en cuanto a los orígenes de los aparatos que actuaron en la ejecución y proyectación. Estos momentos están caracterizados por las diferentes relaciones que establecieron los distintos organismos estatales entre si, a saber: Primer momento, está relacionado con la hegemonía de los organismos del estado nacional, nos referimos a los planes de aprovisionamiento de agua por parte de Obras Sanitaria de la Nación, con diversas modalidades de captación. antes de la década del sesenta, el desarrollo ulterior de los aparatos del estado provincial, determinó su incorporación en el accionar con los nacionales.

Segundo Momento; Los aparatos provinciales tomarán como po- lítica la contratación de consultoras externas, encargándoles planeamientos integrales del territorio, dejando para si las obras de influencia local.

Tercer momento: tiene la característica de abundancia, es decir que hay una superposición de aparatos que operan sobre la problemática, contabilizamos diecisiete o dieciocho, independientemente de la ley $N^{\circ} 3.230$ que centraliza en un único aparato estatal que hasta el presente no se ha materializado.

La intención del trabajo no radica en desarrollar una arqueología de los aparatos del estado pero si sus "ejecuciones".

Es una decisión metodológica presentar los planes que se han desplegado en los últimos tres lustros con periodizaciones quinquenales, esta partición temporal obedece a la necesidad de asociar los planes y los gobiernos que se han sucedido en el manejo de la cosa pública.

El despliegue de los planes no contiene a todos, básicamente está los más importantes. Queda por incorporar planes desarrollados en el período `70 al ' 82 .

No haremos una descripción pormenorizada de los planes ya que escapa a la intención de este trabajo. Sí intentaremos presentar las características generales que permitan mostrarnos que es lo que se planificaba cuando se ejecutaban los planes.

Una primera mirada a los mapas encontraremos un hecho que ha permanecido en los treinta años de planes que estamos analizando cual es, el despliegue del planeamiento estatal volcado al Domo Al- 


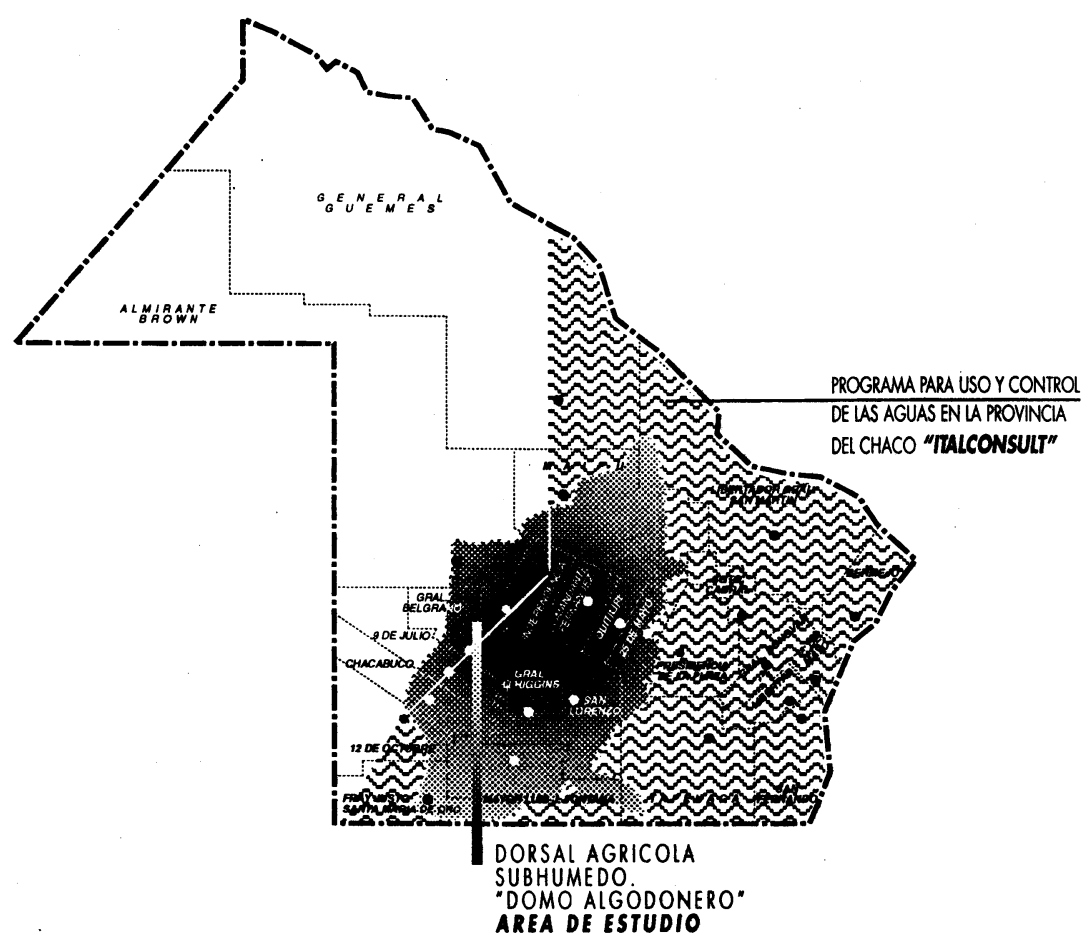

Los Planes en el período $1960 \cdot 1965$

godonero.

Es la continuación del desarrollo de este territorio como señalábamos desde sus inicios en 1920 con el auge de la producción algodonera.

Los problemas principales a resolver será por un lado tener agua para las épocas de sequías y por otro, controlar los excesos de agua por lluvia. Las dos situaciones se alternan. Afectando a la producción cuando los tiempos son largos de una u otra situación climatológica.

La larga lista de planes ha tomado como objetivo a solucionar, las dos situaciones básicamente, haciendo combinaciones donde prevalecía una de las características sobre otra.
Una segunda mirada estaría en los tiempos de desarrollo de los planes. Coincide en que los planes que no están bajo la órbita directa del estado provincial han permanecido como la Comisión de Recuperación del Río Bermejo y Los Bajos Submeridionales.

Merecería incluirse dentro de la categoría de "permanente" al Plan de Defensa contra Inundaciones, de la ciudad de Resistencia

Desde 1954 estaba la preocupación de la defensa de la ciudad capital. Al lanzarse el plan de defensa en 1982, éste actuaba en todo el ámbito provincial, limitando su accionar a la ciudad de Resistencia desde marzo de 1987. De esa fecha es un organismo descentralizado del Poder Ejecutivo Provincial. 


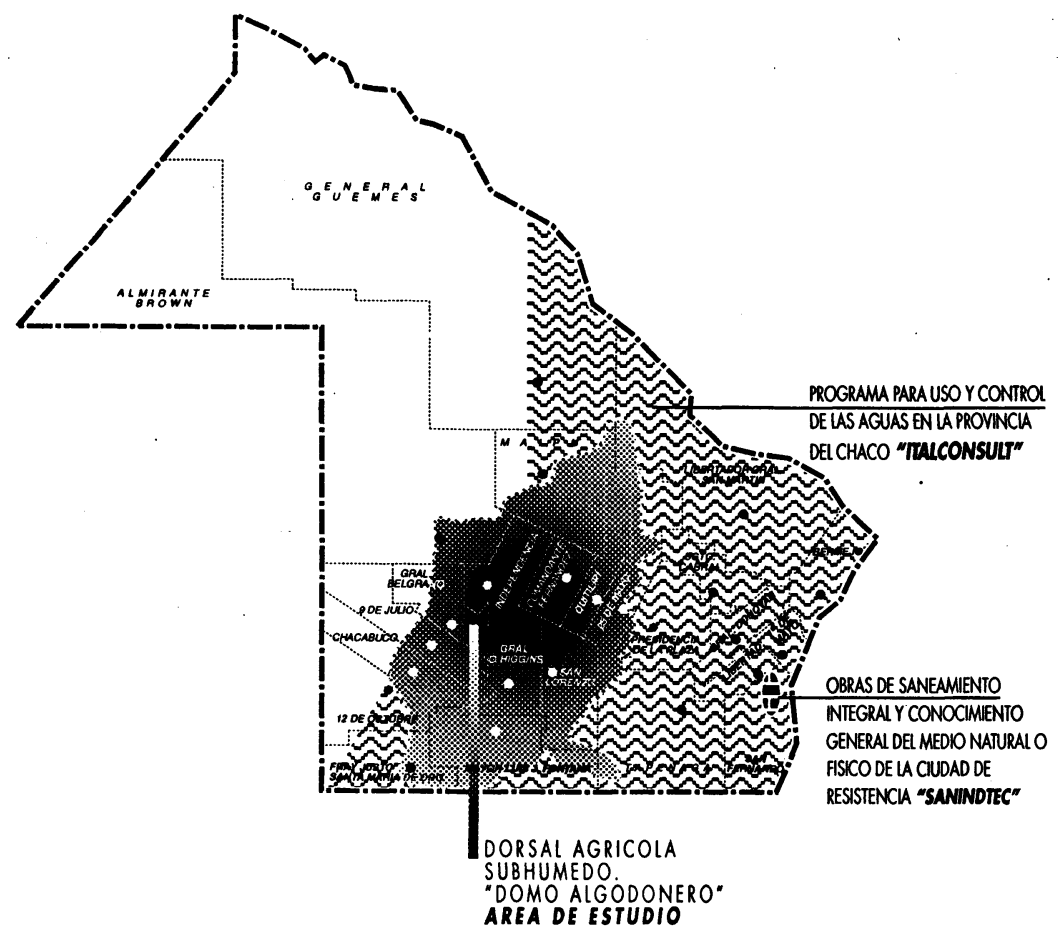

\section{Los Planes en el periodo $1965 \cdot 1970$}

Han sido estos dos planes territoriales rurales y urbano los que permanecieron

Los planes están ligados a los gobiernos del régimen y su permanencia está condicionada a su mentores.

Los planeamientos que están relacionados con ciertas estrategia extra provincial o para ser más precisos, cuando el estado provincial acuerda intereses con otros estados provinciales cual son los dos planes rurales que describíamos, esta relación de estado a estado da otra cualidad en el aparato que lo hace permanecer.

Para el caso del Plan de Defensa Contra Inundaciones, su presencia es vital para la ciudad y esto involucra otras relaciones, principalmen- te con la comunidad, con los municipios, con los proveedores etc.,.

Una tercera pondría el acento sobre el domo algodonero como área donde los planes tienen ingerencia en forma directa o indirecta.

Desde el ITALCONSULT, cuya preocupación central estaba en armar una base de información fidedigna para elaborar a pàrtir de allí las obras necesarias para el control de las aguas. Este importante plan sể vio fracasado cuando el golpe de estado de 1966 decidió reducir al ámbito de la literatura, quedando los documentos elaborados como consulta para los planes posteriores.

Al no concretarse este plan se perdió una oportunidad histórica debido a que hasta el momento no 


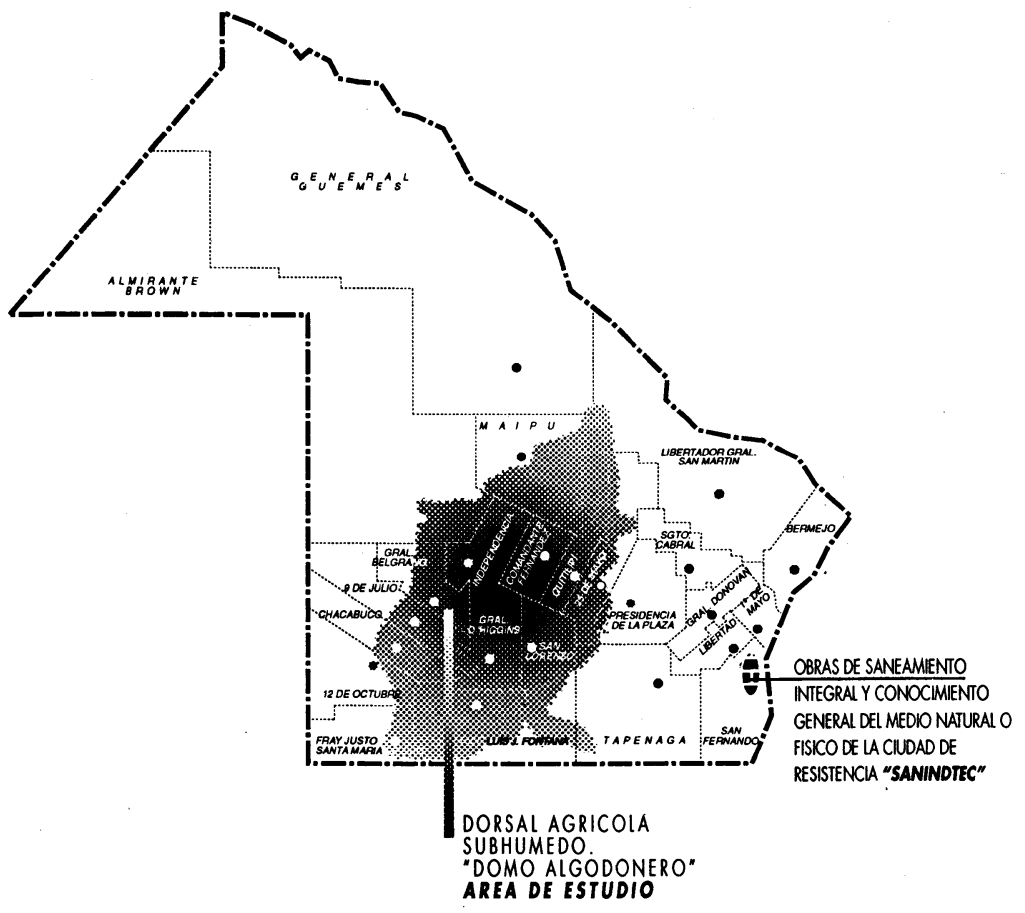

Los Planes en el periodo $1970 \cdot 1975$

hay datos generales confiables que permita tener un punto de partida para realizar la decisiones territoriales.

La estrategia estatal de los grandes planes estuvo siempre supeditado a la permanencias de las alianza estado-capital. ITALCONSULT no sobrevive al golpe del ` 66 , siendo un plan de largo plazo que contemplaba específicamente la optimización de la producción del domo algodonero.

Al ser desplazado la alianza anterior por una nueva que detenta el aparato del estado, las estrategia de control mudan conforme a sus intereses. En términos absolutos estos no diferirán con las anteriores estrategias. La nueva situación institucional contemplará nuevos elementos cual es los movimientos de productores agropecuarios que comenzaban a constituirse en movimiento social.

Los tiempos del plan que estamos haciendo referencia no contempla la dinámica de las estructuras sociales. A la desactivación del plan devino una política territorial donde se producía la captación de productores a los Consorcios Zonales.

La estrategia territorial de la dictadura fue actuar en el terreno de los productores agropecuarios, para descomprimir el movimiento social que se estaba creando. Los aparatos del estado operaron en directa relación con los movimientos sociales, intentado dar soluciones a los problemas puntuales gene- 


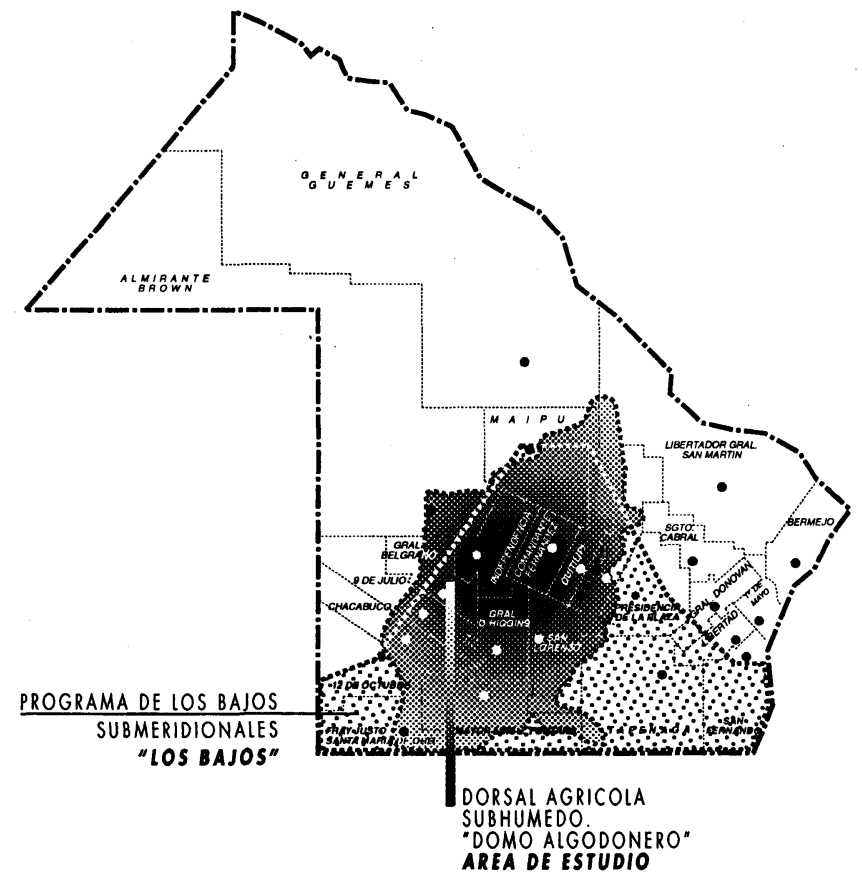

Los Planes en el período $1975 \cdot 1980$

rados por las aguas superficiales.

El plan no será herramienta idónea en el marco de las exigencias de la coyuntura para contener las bases sociales de los sectores más dinámicos de los productores. La coyuntura es delegada a los aparatos, que al institucionalizar mediantes los Consorcios Zonales, demarcaran y controlaran las acciones de construir canales de los productores.

Esta descripción es importante porque a partir de esta situación se instauran dos territorios dentro de la estrategias del estado.

Uno referido a un proceso de reconversión a acciones controladas por el estado cual es las organizaciones de productores y otra la de los planes. Nótese que el mapa del período 1970-1975, no aparecen planes que operen en el área de estudio. Es momento donde se está desarrollando el proceso descripto en párrafo anterior.

En el interregno de 1970-1975 se crea El plan de los bajos submeridionales, surge por la necesidad múltiples de productores Santigueños, Chaqueños y Santafesinos, para controlar los efectos de las inundaciones que provoca esta subregión del Chaco Argentino. La jefatura del aparato involucrará a las provincias del Chaco, Santa Fe y Santiago del Estero. En la parte correspondiente al Chaco, sus acciones estarán en directa relación con el Domo ya que se trata de conducir el fluido de esa sub-región pasando por los bajos submeridio- 


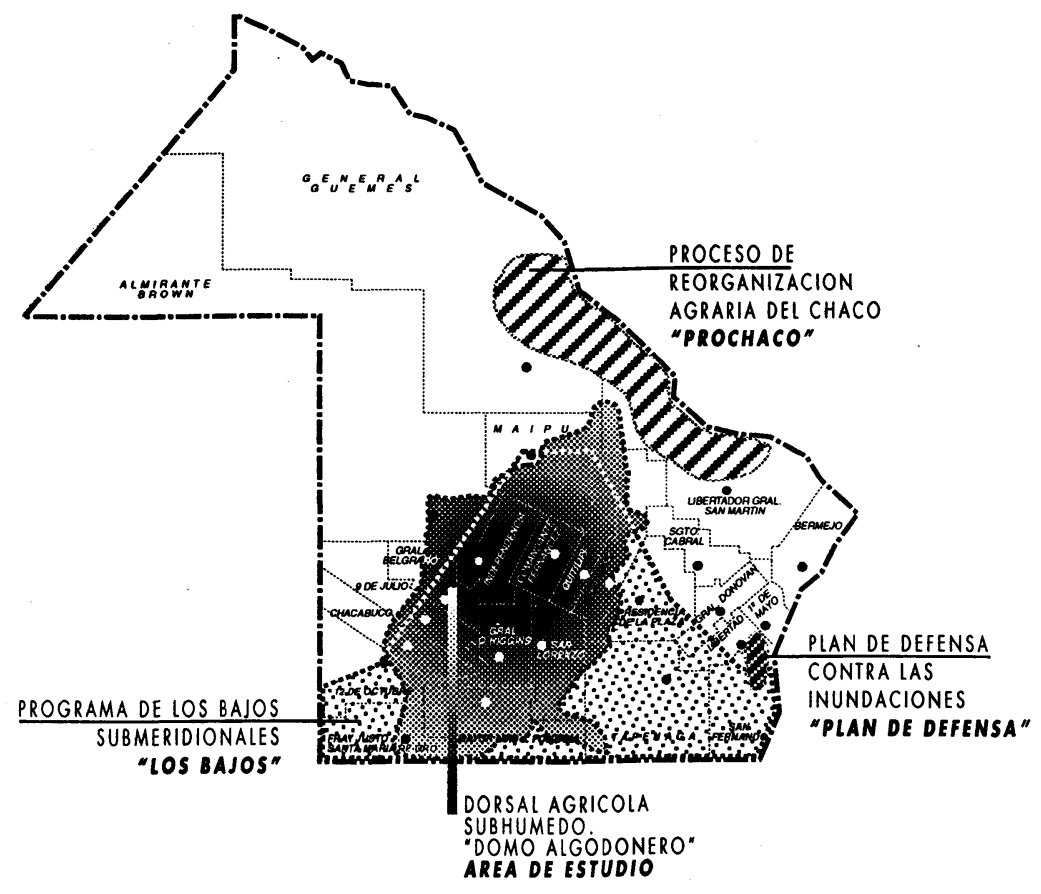

\section{Los Planes en el periodo $1980 \cdot 1985$}

nales desagotando en el Río Paraná.

Será una constante en cuanto a las políticas del estado superponer acciones. Una situación similar al período anterior se genera cuando en 1981 la dictadura implantada en el ' 76 crea las Comisiones de Manejo de Agua y Suelo, perfeccionando el mecanismo de los Consorcios Zonales. Aparentemente la división de tareas quedó establecido de la siguiente manera: la COMAS hacía los canales menores y los Bajos los canales colectores principales. Esta división permanecerá hasta el presente.

Estos aparatos y planes son mantenido y optimizados en el quinquenio ' 80 '85. La dictadura genera el PROCHACO, para abastecer de agua a los departamentos del no- roeste chaqueño, respondiendo a la intención de ampliar las fronteras agropecuarias incorporando la zona vacía del Impenetrable. El gobierno publicitariamente se paraba sobre la idea de una segunda colonización del Chaco, así como los predecesores tomaron el oriente chaqueño, luego la zona centro, los hijos de los hijos explotarían una sub-región que hasta el momento estaba casi inexplotada. Este plan respondía a la estrategia de las alianzas del estado provincial-nacional y los sectores de capital ligados al comercio internacional. Este período no dura mas de dos años donde por condiciones políticas internas (guerra de Malvinas) cambios en la relaciones internacionales, etc., el modelo cesa. Pero fue un período donde el estado por un lado conti- 


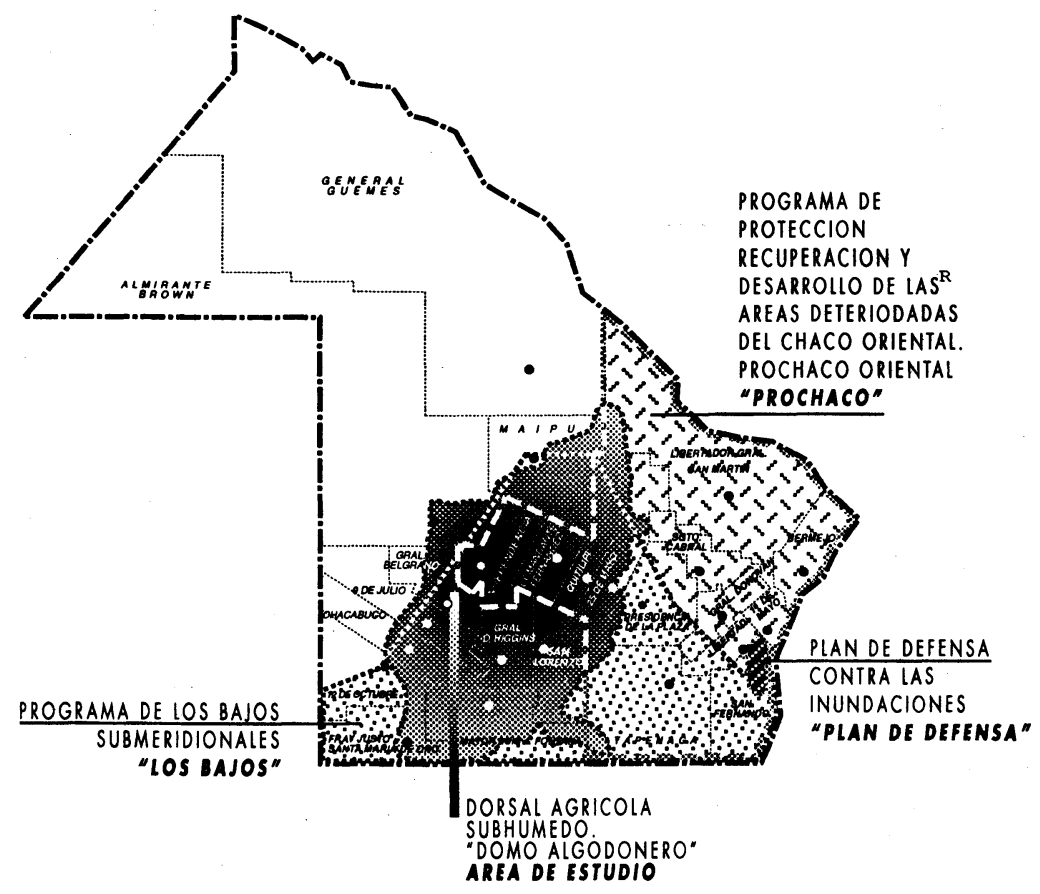

\section{Los Planes en el periodo $1985 \cdot 1990$}

núa con los planes y programas del Domo en función de las nuevas condiciones sociales emergentes del terrorrismo de estado, y por el otro respondió a la demanda del capital de incorporar la oferta de tierras e infraestructura estatal para un nuevo proyecto del capital en el impenetrable.

Los gobiernos democráticos del '84 al 90 se han distribuidos las COMAS conforme la composición de los votos de los dos partidos que tuvieron mas representatividad en las elecciones, de allí que hubieron COMAS Justicialistas o Radicales. Se estableció un nuevo punterismo territorial, esto trae a cuenta que el período analizado no se han producido planes de envergadura que tomara los aspectos de las aguas su- perficiales. Se continuó con los $\mathrm{Ba}$ jos que logran también una fuerte inversión construyendo los canales principales. Pero como habíamos descrito, las COMAS en este período son priorizadas por la inversión estatal de acuerdo a las estrategias electorales. La paradoja está que en este momento no lhy autoridad estatal que pueda determinar con claridad que obras han hecho las COMAS. Lo concreto que han modificado los caudales y los paisajes hídricos, y hoy los canales principales de los Bajos están presentando deficiencias en la conducción del fluido. La tarea actual de los Bajos Submeridionales es relevar que han producido las COMAS para poder rediseñar los canales principales o crear otros. 
El otro plan que tomara el domo será el PROCHACO, que más bien está ligado a objetivos de conservación y explotación racional de los recursos naturales.

Cabría una aclaración para el lector, los planes que no hemos descriptos o no están mencionado obedece a que por un lado no tenían referencia directa al área de estudio o al momento de elaborar este artículo la información no estuvo disponible.

\section{Reflexión a modo de final y de comienzo}

No podríamos entender el espacio territorial de la provincia sin vincular la expansión del capital y el estado acompañando esta dinámica.

Dos modelos de control se han desplegado, el plan y los aparatos, estos últimos catalizaron una práctica socio-cultural desarrollada por los productores agropecuarios. La contrapartida fue estatizar sus pro- blemas infraestructurales, convirtiendo a las COMAS, en un factor de poder estable.

El plan vinculó los intereses generales del capital creando una situación donde se produciría una distribución de recursos.

El plan está sujeto a la permanencia del gobierno que lo impulsa, en la visión restropectiva que hemos realizado, resaltamos un aspecto cual es la territorialización de áreas donde los recurso nuevos por explotar están en función de ciertas concordancias con quienes completaría el circuito productivo. Este contrato donde una parte pone sus recursos y otra establece un dominio es la génesis de los planes. También determina su debilidad. Dado que el estado, dispone de los recursos que en términos absolutos no le pertenece, frente a un sector que lo usufructuaría, (el capital) un recurso que está en disputa permanente con el otro factor de la producción de suelo cuales son los movimiento sociales. 